\title{
O TRABALHO DOCENTE FRENTE AO DESENVOLVIMENTO COGNITIVO E SOCIOAFETIVO DISCENTE
}

\author{
Maria de Lourdes Ramos da Silva ${ }^{\text {iD } 1}$ e Jonas Alves da Silva Junior ${ }^{\text {DD } 2}$
}

\section{Resumo}

Este ensaio se propõe a tecer reflexões sobre o trabalho docente, com base em teóricos fundamentais no debate acerca das dimensões da profissionalidade docente, com ênfase na cognitiva e socioafetiva. A primeira se refere à construção dos diversos conhecimentos desenvolvidos com base nos conteúdos curriculares propostos; e a segunda refere-se à identificação dos aspectos socioafetivos que interferem nos relacionamentos discentes e na aprendizagem. Respaldado nessa diferenciação, analisa-se o trabalho desenvolvido pelo professor na escola, acentuando-se o caráter interdisciplinar de cada função enquanto aspectos complementares do trabalho docente, além de delinear os desafios e complexidades do fazer pedagógico do professor frente à pandemia da Covid-19.

Palavras-chave: Profissionalidade docente; Trabalho docente; Dimensão cognitive; Dimensão socioafetiva.

\section{TEACHING WORK IN FRONT OF DISCENT COGNITIVE AND SOCIOAFFECTIVE DEVELOPMENT}

\section{Abstract}

This essay brings reflections on teaching work based on the main theoretical approaches to teacher professionalism, highlighting its cognitive and socioaffective dimensions. The cognitive dimension refers to the acquisition of content knowledge based on curriculum programs and the socio-affective dimension refers to the identification of socio-affective aspects that interfere in student relationships and learning. Based on this differentiation, we analyse the daily work developed by teachers in the classroom, emphasizing the interdisciplinary character of each function as complementary aspects of teaching practices, the complexities of teaching and new challenges posed by the Covid-19 pandemic.

Keywords: Teacher Professionalism. Teacher Identity. Cognitive Dimension. Socio-Affective Dimension.

${ }^{1}$ Doutorado em Ciências da Educação pela Universidade Complutense de Madri. Professora Livre-docente da Faculdade de Educação da Universidade de São Paulo. Docente do Programa de Pós-Graduação em Educação da USP.

${ }^{2}$ Doutor em Educação pela Universidade de São Paulo (FE/USP) e docente do Programa de Pós-Graduação em Educação (PPGEDUC) e da graduação da Universidade Federal Rural do Rio de Janeiro (UFRRJ). 


\section{Introdução}

O recente panorama da educação, sobretudo por conta da pandemia da Covid-19, decretada pela Organização Mundial de Saúde a partir de 11 de março de 2020, alia tensões, contrassensos e valores presentes na conjuntura sóciopolítico-econômica brasileira. Esses pontos promovem o debate no cenário acadêmico e sinalizam princípios que tornam a discussão instigante, mas, também, fragmentada.

Essa conjuntura é empreendida pela forma como as sociedades estão ordenando políticas e práticas educacionais em tempos de pandemia, evidenciando um contexto incoerente e paradoxal, pela qual se percebe um empenho no ajustamento dos diferentes sistemas de ensino com base em uma lógica externa, da qual professoras e professores não foram "convidados/as" a participar. Em contrapartida, estes são frequentemente responsabilizados pelos problemas da educação brasileira e sempre intimados a realizar cursos de "reciclagem" ou de "capacitação" em programas de formação continuada, ainda mais numa época em que a única possibilidade de ensino, para atender às novas regras sanitárias, foi a EaD (Educação a Distância).

No entanto, desde o início de 2021, as escolas têm se preparam paulatinamente para a volta às aulas presenciais, já que durante a pandemia o ensino foi desenvolvido de forma remota para uma parte dos alunos, ainda que nem todos puderam acessar aulas e atividades online, através de ferramentas como o Google Meet e Zoom, aulas gravadas e atividades supervisionadas por docentes e pais.

Os professores também precisaram se adaptar à nova realidade para desenvolver os diversos assuntos curriculares mediante um ensino remoto emergencial improvisado, cuja duração se estendeu durante todo o ano letivo de 2020. Entretanto, verificamos que o ensino remoto utilizado durante a pandemia só foi possível devido ao crescimento das tecnologias de informação e comunicação (TIC), pois o conhecimento tornou-se um processo dinâmico em permanente transformação e desenvolvimento.

Dessa forma, não se pode omitir a problemática sobre como o docente opera com essa dinâmica pelos diferentes ambientes sociais e pelos discursos neles disponíveis, impulsionados pelos sujeitos com os quais interage, e sobre como (re)constrói identidades mais ou menos consolidadas nesse processo. Tal reflexão é decisiva para que as diferentes instâncias que ofertam cursos de formação docente reconsiderem seu próprio fazer, assim como os currículos definidos para essa finalidade, já que se compreende que os processos de formação do/a professor/a são identitários.

Assim sendo, como a contemporaneidade tem sido modelada pelas tendências da globalização, pelas diretrizes de segurança sanitárias e pelas profundas transformações sociais dela decorrentes, tais questões ramificam-se em diversas áreas, reverberando sobretudo nos conceitos de identidade. Por isso, neste ensaio, proporemos uma reflexão sobre as dimensões da 
profissionalização docente, com base em autores fundamentais na discussão atinente às identidades docentes.

\section{Dimensões da profissionalização docente}

Para Dubar, a identidade é sempre transitória, já que se constrói mediante as diversas experiências de socialização que definem sujeitos e instituições. Por essa razão, se vincula a todos os aspectos da vida, inclusive o profissional, com o qual pode apresentar complementaridade ou contradição (DUBAR, 1995).

Neste sentido, Melucci defende o termo "identização" para expressar o caráter processual, auto-reflexivo e construído da definição de nós mesmos face ao reconhecimento feito pelo outro. Assim, a identidade profissional, com seu caráter de construção coletiva, assume uma influência cada vez maior no processo pessoal de identização proposto pelo autor, à medida que a atividade profissional é uma das principais mediações entre o sujeito e o mundo social (MELUCCI, 2004)

Ao focalizar a identidade profissional docente, Nóvoa defende a ideia de que em seu desenvolvimento há uma simbiose entre o eu pessoal e o profissional, já que se trata de uma profissão impregnada de valores e a relação entre os sujeitos é fundamental. Portanto, o fato de sentir-se professor é o resultado de um processo evolutivo, que se constrói desde o momento da opção pela profissão docente, com base no saber experiencial acumulado, e que resulta do modo como os diversos professores se apropriam dos saberes a serem ensinados e da autonomia com a qual exercem a sua atividade docente. (NOVOA, 1992).

Para Silva (2007), há três dimensões entrelaçadas a considerar na construção da identidade do professor em sua profissionalização: dimensão pessoal, dimensão afetiva e dimensão sócio-políticaEmbora a autora não discrimine uma dimensão cognitiva, considera-se que a dimensão pessoal atribuída por Silva, embora bastante abrangente, inclui a dimensão cognitiva, já que a formação docente pressupõe a aprendizagem de alguns conhecimentos indispensáveis para sua concretização. No magistério, a aprendizagem do trabalho passa por uma escolarização longa, cujo objetivo é possibilitar aos futuros trabalhadores alguns conhecimentos teóricos e técnicos que os preparem para o trabalho a ser desenvolvido. Tal formação deve sempre ser complementada com uma formação prática, com base na experiência docente, que possibilite ao professor se familiarizar com os diversos ambientes de trabalho (TARDIF, 2000).

Outro aspecto importante a considerar quando se trata da identidade docente e sua profissionalização foi a identificação do ofício docente como uma atividade exercida predominantemente pelo sexo feminino e visto como vocação, missão e sacerdócio. Se o exercício do magistério pode representar um avanço na emancipação feminina pela entrada das mulheres no mercado de trabalho, essa visão de sacerdócio torna-se muitas vezes incompatível com o 
sentido da profissionalização e luta por salários considerados adequados. (MARCONDES; LEITE, 2014). Embora a profissionalização docente deva envolver a prestação de um serviço pelo qual se recebe uma remuneração, a exigência de uma formação específica para exercer a profissão, a autonomia e autoridade legitimada de um conhecimento específico e a experiência prática e salários adequados, a profissionalização vista apenas como vocação dificulta a manutenção de homens na profissão, pois não há a identificação necessária.

Ferreira (1996) defende que o estudo do desenvolvimento da profissão docente exige sempre considerar a heterogeneidade que caracteriza este grupo social e ocupacional. Além das diferenças individuais ou afinidades grupais, que distinguem, aproximam ou mesmo opõem uns grupos em relação a outros, é possível encontrar grande diversidade de variáveis que podem ser decisivas nessa heterogeneidade. Entre tais variáveis, podemos apontar as seguintes: nível de ensino no qual os professores trabalham, disciplina ou disciplinas que lecionam, situação profissional que mantém junto à instituição escolar, habilitação profissional, tempo de exercício no magistério e experiência docente em diversos cargos e funções relacionadas ao sistema educativo (FERREIRA, 1996). Tais variáveis são decisivas e explicam a diversidade acentuada existente entre os professores e grupos de professores.

Morgado, por sua vez, defende que a profissionalização docente não pode restringir-se ao domínio de um conjunto de conhecimentos científicos com base nos conteúdos curriculares ou de um conjunto de conhecimentos metodológicos relacionados às ciências da educação, já que a construção desse saber deve mobilizar todos esses conhecimentos em torno de uma situação concreta educativa, com vistas a possibilitar a ampliação das diversas aprendizagens dos alunos (MORGADO, 2011).

Logo, a compreensão das relações possíveis entre o processo educativo, a escola e a cultura torna-se fundamental nessa mobilização. O professor, segundo o autor "somente assim poderá apropriar-se dos verdadeiros sentidos que subjazem aos processos de aprendizagem e lidar, de forma profícua, com as diferenças que caracterizam os alunos e os contextos com que trabalha cotidianamente" (MORGADO, 2011, p. 798).

Portanto, ainda que a educação escolar tenha como objetivo possibilitar aos alunos a construção de conhecimentos e o desenvolvimento de habilidades, hábitos e atitudes, não podemos esquecer que os conteúdos expressos nessa construção, bem como os diversos processos por meio dos quais esses conteúdos são transmitidos, são sempre, de alguma forma, impregnados de sentimentos, valores e atitudes que Ihes dão sustentação. Segundo Gatti et al:

A educação escolar, em seus diferentes níveis, tipos e formatos, constitui-se como o espaço em que ao mesmo tempo preservamse conhecimentos, valores, e se criam possibilidades de revisão do já constituído e de assentamento de bases para transformações culturais, científicas e sociais, considerando que, conhecimentos são imprescindíveis à preservação da vida humana e social, ao 
trato com o meio ambiente, e importantes para fundamentar valores e uma ética social. (GATTI et al, 2019, p.11)

Os diversos conteúdos ensinados pelo professor em sala de aula revestem-se sempre de uma forma subjetiva de perceber e de interpretar os conhecimentos ministrados e, por essa razão, a atividade educativa deve ser sempre observada em seu aspecto bifacial. Se, por um lado, pressupõe uma ação relacionada à ampliação dos conhecimentos por parte dos alunos, por outro lado pressupõe uma opção diante desses conhecimentos, com base em valores e atitudes incorporadas.

Portanto, se considerarmos que a tarefa essencial da educação é a formação do educando em seus múltiplos aspectos, temos que admitir que tal formação, à medida que recai sobre as atitudes do sujeito face ao mundo e face a si próprio, não pode ficar restrita à aquisição de conhecimentos, mas fundamentalmente a opções éticas, morais e escolhas de valores. Assim,

[...] de nada adianta ao professor ser competente em relação ao conteúdo a ser transmitido e à metodologia utilizada em sala de aula, se ele não for ético em suas relações com os alunos e com os seus colegas, pois a ética é imprescindível em qualquer relação profissional. Além disso, a competência para se colocar no lugar dos alunos, de perceber as coisas como eles as percebem de valorizar a qualidades que os alunos possuem são aspectos socioafetivos cruciais para que o professor desempenhe sua tarefa com competência e êxito (SILVA, 2020, p. 58).

Dessa forma, podemos discriminar sempre duas dimensões interdependentes na ação desenvolvida pela escola: a cognitiva e a socioafetiva que, a nosso ver, inclui a dimensão política nomeada por Silva (2007). A dimensão cognitiva refere-se à construção dos diversos conhecimentos, procedimentos e técnicas e tem como finalidade conduzir os alunos ao conhecimento das possibilidades e limitações inerentes aos diversos campos de trabalho e ambiente sociocultural. Já a dimensão socioafetiva e axiológica refere-se ao campo dos sentimentos, valores, limites sociais e dizem respeito às atitudes assumidas pelos alunos diante das diversas situações de vida, bem como às avaliações políticas que fazemos a todo o momento em nossa existência diante dos diversos acontecimentos sociais.

\section{0 professor e a dimensão cognitiva do ensino}

Diversos autores denunciam que as funções dos professores se modificaram de forma substancial nas últimas décadas, como Marchesi (2008) e Esteve (1999), entre outros. Tais mudanças dizem respeito principalmente à exigência com relação ao aumento de funções a ser desempenhadas pelas escolas, à capacidade por parte das escolas de ter acesso às informações e de saber selecioná-las à flexibilidade, à inovação e à capacidade das pessoas e das instituições de ampliar seus conhecimentos continuamente. 
Para Esteve (1999), algumas mudanças alteraram de modo radical o alcance do trabalho a ser desenvolvido pelos professores, tais como: aumento das exigências em relação à atuação dos professores na instituição escolar, desenvolvimento de fontes de informação alternativas à escola, menor valorização social do professor, mudanças de expectativas familiares e sociais em relação à escola, mudanças dos conteúdos curriculares, mudanças nas relações professor-aluno e fragmentação do trabalho do professor. Todas essas mudanças repercutem no trabalho docente, causando um mal-estar docente que influencia decisivamente o processo ensino e de aprendizagem. Segundo Esteve:

O isolamento é a característica comum mais importante dos professores seriamente afetados pelo desajustamento provocado pela mudança social. A formação permanente deve construir-se a partir de uma rede de comunicação, que não se deve reduzir ao âmbito dos conteúdos acadêmicos, incluindo também os problemas metodológicos, pessoais e sociais que, continuamente, se entrelaçam com as situações de ensino. A inovação educativa está sempre ligada à existência das equipas de trabalho que abordam os problemas em comum, refletindo sobre os sucessos e as dificuldades, adaptando e melhorando as práticas de intervenção (objetivos, métodos e conteúdos). (ESTEVE, 1999, p. 119).

Especificamente quanto ao processo de ensino e aprendizagem, verificase uma predominância da imagem na forma como os alunos processam a informação e uma dificuldade acentuada no controle interno de atenção. Assim, a tarefa de ensinar as novas gerações enfrenta inúmeros dilemas e contradições, pois não há clareza quanto ao que envolve ensinar, de que forma isso pode ser feito e quais valores precisam ser defendidos, nem sobre a atitude que deve ser adequada em face dos inúmeros problemas que enfrentamos com a Covid-19.

Diante disso, o fato de saber envolver os alunos em suas aprendizagens e propiciar a ampliação de seus conhecimentos é um aspecto muito importante no cotidiano da função docente, como defende Marchesi:

Em certas ocasiões, os professores consideram suficiente, para o bom desempenho de sua atividade, quando são capazes de projetar situações de aprendizagem bem-estruturadas e sequenciadas que facilitem aos alunos a ampliação de seus conhecimentos. Não há dúvida de que é uma competência necessária - nada simples, por outro lado -, que exige traduzir os conteúdos da disciplina em objetivos de ensino já adequados segundo os conhecimentos prévios dos alunos. Contudo, é necessário dizer que essa é uma competência insuficiente. É preciso dar um passo a mais e incorporar, entre os objetivos prioritários do ensino, a necessidade de despertar o desejo do saber dos alunos e de fazer com que se envolvam na atividade de aprender. É um objetivo ainda mais difícil quando se constata que inúmeros alunos praticamente não estão interessados no que é 
apresentado na sala de aula e estão ali mais por "imperativo legal" do que por vontade própria. (MARCHESI, 2008, p. 60).

Entre os objetivos prioritários do ensino, é preciso considerar a necessidade de despertar o desejo do saber nos diversos alunos e propiciar seu envolvimento no processo de aprender. Neste sentido, a atitude de desinteresse e falta de motivação por parte de determinados alunos se traduz muitas vezes na incapacidade de entender as tarefas escolares e de tentar realizá-las, na ausência de entender o sentido no esforço que é necessário e na sensação de inutilidade da atividade escolar e perda da autoestima.

Logo, um aproveitamento escolar insuficiente pode apresentar diversas razões. Pode significar desinteresse e apatia e, neste caso, tais comportamentos podem ser percebidos pelos professores como demonstração de pouco esforço por parte dos alunos. Atualmente, parece que cada vez mais o esforço "saiu de moda" e tudo o que causa qualquer constrangimento se desvaloriza, já que se cultua cada vez mais o desejo e a sua satisfação imediata. Entretanto, esse individualismo exacerbado leva fatalmente à fraqueza da vontade e isso se reflete de forma indelével na educação escolar, seja qual for o nível de escolaridade de que se trate.

Mas além de desinteresse e apatia, um aproveitamento escolar insuficiente pode denunciar bloqueios frente a determinadas disciplinas, ou pode, ainda, tratar-se de dificuldades relacionadas à interação entre professores e alunos. Nesses casos, qualquer mudança significativa envolve o esforço de reformular a maneira como professores e alunos interagem, já que frequentemente esses aspectos são configurados em imagens difíceis de se visualizarem nitidamente.

Por essa razão, é necessário identificar dois aspectos básicos que devem ser considerados tanto na dimensão cognitiva e socioafetiva desenvolvida pela instituição escolar. O primeiro se refere à verificação do progresso obtido pelos alunos em relação às metas educativas previstas e o segundo se refere à identificação dos aspectos do ensino que interferem no desenvolvimento educativo, tais como: adequação do programa à realidade dos alunos, procedimentos de ensino utilizados, material didático disponível, ambiente físico-social no qual se insere os alunos tanto na escola como fora dela.

Entretanto, às vezes se apresenta uma outra dificuldade relacionada aos conteúdos de ensino. Neste sentido, Arroyo (2013) denuncia o fato de que a cultura escolar fica bloqueada nas polarizações materializadas nas grades escolares, que estabelecem hierarquias profissionais e laborais, e acabam por hierarquizar a própria cultura escolar e profissional da realidade social de que se trate:

De tanto viver, planejar e agir, dentro das grades curriculares, nós pensamos e pensamos o mundo, a sociedade e a história, os educandos, e sobretudo pensamos o conhecimento e a cultura gradeados, hierarquizados. Separamos a cultura nobre da menos nobre, o conhecimento mais científico e mais sério, do menos 
científico e menos sério, o mais valorizado pelo mercado, do menos valorizado. As matérias mais exigentes das mais fáceis de levar. 0 que cai ou não nos concursos, nos provões, no vestibular. Separamos os saberes mais importantes para a vida dos descartáveis (ARROYO, 2013, p 211)

À medida que as políticas educacionais se relacionam cada vez mais à globalização e às transformações causadas pelo sistema capitalista na era contemporânea, acentua-se a vinculação entre a educação e o sistema econômico e o discurso que cada vez mais influencia a educação se vincula ao mercado produtivo que visa formar o sujeito para o mercado de trabalho e para a empregabilidade.

Nesta direção, as pesquisas de Marcondes e Leite (2014) revelam o poder que as políticas de avaliação têm assumido na definição das práticas pedagógicas e curriculares das escolas. Tais avaliações propõem um tipo de aprendizagem que deve ser mensurada por meio de exames padronizados que na maioria das vezes desconsideram as diversas realidades dos contextos escolares, as peculiaridades dos alunos e sua trajetória e termina por responsabilizar os professores pelo desempenho dos alunos. Segundo Esteve:

A chave do mal-estar docente está na desvalorização do trabalho do professor, evidente no nosso contexto social, e nas deficientes condições de trabalho do professor na sala de aula, que o obrigam a uma atuação medíocre, pela qual acaba sempre por ser considerado responsável. (ESTEVE, 1999, p, 120)

Esses estudos permitem concluir que, a partir dos resultados das avaliações padronizadas e dos rankings que são construídos, há uma acentuação da competição entre professores e escolas, substituindo a lógica de aprendizagem pela lógica do controle. Entretanto, essas duas lógicas são irreconciliáveis. Na lógica de aprendizagem, o conhecimento é visto como uma produção cultural do aluno, ensinar é um processo coletivo e a avaliação do aluno é diagnóstica. Já na lógica do controle, há ênfase na transmissão de conhecimentos e a avaliação é usada como controle da aquisição de conhecimentos e para classificar alunos e escolas (MARCONDES; LEITE, 2014).

Segundo Marchesi (2008), para desenvolver a função de despertar o interesse de aprendizagem por parte de seus alunos, os professores necessitam desenvolver quatro habilidades básicas:

1) que o docente esteja, ele mesmo, interessado no conhecimento que pretende que os alunos aprendam, apresentando facilidade em sua transmissão;

2) que consiga relacionar o conteúdo aprendido na sala de aula com o que o aluno vivencia fora dela, bem como trazer acontecimentos ocorridos ao redor da escola para serem discutidos em classe;

3) que seja capaz de facilitar o diálogo, a participação e a colaboração entre os alunos; 
4) que possa elaborar situações de aprendizagem variadas e adaptadas ao contexto de cada classe.

Todos esses aspectos exigem do docente flexibilidade mental, segurança emocional e criatividade e o colocam à frente a uma nova situação de ensino, que por sua vez exige flexibilização curricular, disponibilidade de um maior número de meios materiais e humanos e a busca de novas relações entre o conhecimento e as exigências do desenvolvimento sociocultural de sua época, que exige novas respostas alternativas. O que instiga os educadores a deslocar seus saberes docentes para outra forma de se conceber o ensino? Quais são os constrassensos intrinsecos à nova realidade no ensino que mais lhes afligem? De que maneira esquadrinham possibilidades para suplantar ou minorar tais incongruências, para, assim, poderem operar num universo de sentidos e significados?

Trata-se de um contexto multifacetado e difícil, pois tem relação desde a falta de acesso e apoio tecnológico dos docentes e dos alunos; a parca experiência dos profissionais da educação e a insuficiente formação preliminar com vistas ao domínio de tecnologias para a execução do ensino remoto; até o cenário de vulnerabilidade de muitos alunos.

Dessa forma, faz-se necessário a implicação com as construções subjacentes às práticas docentes, no interior da conjuntura ordenada tanto pelo atual panorama pandêmico quanto pela proposição de ensino remoto. A forma como os processos estão sendo guiados pelas redes públicas e privadas de ensino são suscetíveis a confluir para aprovação, recusa ou reajustes próprios dos professores, conforme a articulação com a atividade de ensino e a construção do trabalho, que surge do ensino remoto e das implicações psíquicas ocasionadas pelas consequências da pandemia.

São essas questões que impulsionam este ensaio, levando-nos a refletir sobre as ações pedagógicas que estão em curso, o grau de autonomia e de formação exigidos e assegurados, nesta conjuntura de exceção, durante o tempo em que as medidas de isolamento social perduram.

\section{Dimensão socioafetiva do ensino}

O desenvolvimento da vida socioafetiva dos alunos é um dos objetivos importantes da educação escolar, mas que nem sempre é considerado pelos professores na proporção devida. Na maioria das vezes, a preocupação dos professores com o equilíbrio emocional dos alunos se manifesta apenas quando percebem que esses aspectos atrapalham o aproveitamento dos alunos nos estudos. Como afirma Savater (2006)

O desempenho produtivo e o desempenho cidadão requerem o desenvolvimento de uma série de capacidades (...) que não se formam nem espontaneamente através da mera aquisição de informações ou conhecimentos. A escola - ou, para sermos mais prudentes, as formas institucionalizadas de educação - deve, em síntese, formar não só o núcleo básico do desenvolvimento 
cognitivo, mas também o núcleo básico da personalidade. Nem sequer o mais estreito utilitarismo autoriza hoje - e provavelmente nunca autorizou - a que subestimemos a formação social e indagadora do caráter em benefício da aprendizagem de dados ou procedimentos técnicos. (SAVATER, 2006, p. 57-58).

Entretanto, como denunciam Sastre e Moreno (2002), a inteligência, enquanto função biológica, está aberta ao conhecimento de modo geral, embora o desenvolvimento do conhecimento no campo afetivo e no das relações interpessoais nem sempre seja considerado como deveria. Isto se deve ao fato de que permaneceu enraizada em nossa cultura a crença de que a razão e as emoções são aspectos separados e distintos. Entretanto, estudos recentes no campo da neuropsicologia evidenciam que não é possível considerar o desenvolvimento de uma sem levar em consideração o desenvolvimento da outra, já que são aspectos interdependentes e entrelaçados. Assim, diversas pesquisas desenvolvidas sobre o cérebro emocional corroboram as relações existentes entre as emoções, sentimentos, habilidades cognitivas, as tomadas de decisões e a construção da identidade da pessoa. Damásio afirma de modo categórico:

É esse o erro de Descartes: a separação abissal entre o corpo e a mente, entre a substância corporal, infinitamente divisível, com volume, com dimensões e com um funcionamento mecânico, de um lado, e a substância mental, indivisível, sem volume, sem dimensões e inatingível, de outro; a sugestão de que o raciocínio, o juízo moral e o sofrimento adveniente da dor física ou agitação emocional poderiam existir independentemente do corpo. Especificamente: a separação das operações mais refinadas da mente, para um lado, e da estrutura e funcionamento do organismo biológico, para o outro. (DAMASIO, 1996, p 280)

Segundo o autor, a influência dos sentimentos sobre o funcionamento cerebral é intensa, já que sua presença no cérebro constitui o marco de referência no qual se elabora o pensamento. Logo, uma integração mais harmoniosa entre razão e sentimentos nos permitirá conhecer nossos sentimentos e utilizá-los de maneira mais proveitosa em nossa vida cotidiana.

No campo da psicologia, existem diversos trabalhos que se debruçam sobre as possíveis interações entre cognição e afetividade, como os de Piaget (1970), que considerava os sentimentos como o motor que impulsiona a ação. Além dele, os trabalhos de Gardner (1994), sobre inteligências múltiplas assumem uma abordagem pluralista, pois admitem facetas ou estilos diferenciados e contrastantes de inteligência. Goleman, particularmente, desenvolveu o papel das emoções no comportamento humano (GOLEMAN, 1995).

Gardner (1994) assume uma abordagem pluralista, pois admite facetas ou estilos diferenciados e contrastantes de inteligência, salientando as seguintes: linguística (habilidade relacionada à linguagem escrita e oral), lógico- 
matemática (capacidade de raciocínio lógico e matemático), espacial (capacidade de formar um modelo mental de um mundo espacial e de ser capaz de manobrar e operar utilizando esse modelo), musical (relacionada às diversas maneiras para compor e absorver música), corporal-cinestésica (resolver problemas ou de elaborar produtos utilizando o corpo inteiro ou partes do corpo), interpessoal (capacidade de entender as outras pessoas em relação ao que as motiva, ao modo como trabalham e às formas de cooperar com elas) e a intrapessoal (capacidade de formar um modelo de si mesmo e de utilizar esse modelo para operar efetivamente na vida).

Posteriormente, em 2000, Gardner acrescentou a inteligência naturalist a, que foi entendida como a capacidade de discriminar ou de classificar diferentes espécies de fauna e flora ou de formações naturais como montanhas ou pedras. Além dela, começou a apontar a possibilidade de incluir uma nona inteligência, a existencial, cuja preocupação era a de incluir as questões básicas da vida.

Goleman, por meio de seu livro Inteligência Emocional, publicado em 1995, também despertou grande interesse sobre a temática das emoções. Para o autor, temos dois cérebros, duas mentes e dois tipos de inteligência: a racional e a emocional, pois nosso desempenho na vida sempre irá depender do envolvimento das duas inteligências. Por essa razão, o ensino deve repensar a educação do aluno como uma totalidade, buscando sempre conciliar o desenvolvimento do raciocínio lógico-matemático com o desenvolvimento de algumas aptidões vivenciais básicas que muitas vezes têm sido menosprezadas, tais como: autoconsciência, autocontrole, empatia, intuição, relacionar-se com a tensão, comunicar-se com o outro, autoaceitação, responsabilidade pessoal, assertividade e a busca de soluções para conflitos (GOLEMAN, 1997).

À medida que o desenvolvimento da inteligência é inseparável da afetividade, há sempre, de forma inevitável, uma estreita conexão entre ambas. Se, de um lado, a afetividade pode asfixiar o conhecimento, de outro, pode também fortalecê-lo. Se a faculdade de raciocínio pode diminuir face ao déficit de emoção, o enfraquecimento da capacidade de reagir emocionalmente pode estar na raiz de comportamentos irracionais.

Para que a pessoa possa resolver situações problemáticas de modo satisfatório, é fundamental que consiga descentrar-se do seu próprio ponto de vista para contemplar outro ou outros pontos de vista alternativos e elaborar fusões criativas entre eles, o que envolve necessariamente operações de reciprocidade e de síntese entre contrários. Dessa forma, as habilidades cognitivas dependem do desenvolvimento das habilidades sócio-afetivas, já que o professor, ao facilitar o diálogo, a participação e a colaboração entre os alunos, consegue elaborar situações de aprendizagem variadas e adaptadas ao contexto de cada classe.

Diante disso, a dimensão socioafetiva torna-se um objetivo fundamental do ensino, a ser incluído no projeto educacional das escolas e na ação pedagógica dos professores, uma vez que aponta para um aspecto fundamental do desenvolvimento integral do ser humano, à medida que visa preparar o aluno 
para saber lidar com as diversas situações de vida e a saber empregar os meios disponíveis e mais adequados para resolvê-las. Na verdade, a capacidade de domínio pessoal do aluno, no sentido de aprender como dirigir a própria vida face às adversidades, depende basicamente da habilidade para identificar os diversos problemas a serem resolvidos e de como posicionar-se diante deles.

Assim, a incapacidade de permanecer com aulas presenciais pressionou as redes de ensino de diversos países, incluindo o Brasil, a valer-se de ferramentas digitais para reassumirem as atividades de ensino. Tais transformações demandaram (e continuarão demandando) prudência e adaptação de alunos, professores e gestores educacionais, na medida em que o risco de contágio prosseguir. Aspectos afetivos e sociais foram instigados no que se refere à dinâmica de adaptação a essas ferramentas digitais, com vistas ao processo de ensino-aprendizagem. Segundo Sastre e Moreno,

Se o século passado foi, para a psicologia, o do estudo separado da afetividade e da inteligência, o presente século será, sem dúvida, o de seu estudo conjunto, e isto conduzirá a mudanças muito importantes, não só no terreno da teoria mas também no da aplicação, que repercutirão na vida cotidiana. Justo é reconhecer que, para chegar até aqui, tenham sido necessárias as ideias de pensadores tão brilhantes como Freud, Piaget e muitos outros, que, graças à profundidade de seus trabalhos, nos permitiram superar o pensamento linear e ter acesso a uma visão mais complexa da problemática atual (SASTRE E MORENO, 2002, p. 24).

Não obstante, à medida que o sistema escolar deixa de considerar como inteligentes os conhecimentos relativos ao campo afetivo e às relações interpessoais, esses conhecimentos deixam de ser contemplados no currículo escolar, propiciando uma defasagem cada vez mais acentuada entre a evolução dos processos cognitivos do pensamento e a evolução dos processos afetivos. 0 resultado dessa defasagem nos conduzirá a uma sociedade bem preparada para alcançar inúmeros progressos no campo tecnológico, mas que não consegue resolver seus conflitos emocionais de forma inteligente (GOLEMAN, 1995).

Esta nova realidade tem exigido de docentes e das escolas novos saberes e habilidades para preservação das aprendizagens, dos vínculos e das interações significativas em todas as fases de ensino (NASCIMENTO e SILVA, 2020). Não é crível conceber o panorama local da sala de aula sem levar em consideração os aspectos estruturais, assim como os múltiplos cenários de influência que perpassam as políticas públicas, tanto no que se refere às escolas de educação básica, como também à formação docente. Por isso, democratizar a educação não se trata somente de disponibilizar conteúdo e sobrecarregar os alunos com exercícios e avaliações; tampouco tem a ver com imposição dos professores a uma veloz adaptação a plataformas virtuais em que sequer foram capacitados. Tais estratégias expõem ainda mais os estudantes às suas fragilidades, ao desconsiderar os aspectos subjetivos e socioafetivos na interação escolar. 


\section{Considerações finais}

Em nenhum outro momento anterior, o entrelaçamento da função cognitiva e socioafetiva desenvolvidas pela escola foi tão necessário como no momento atual, em que o retorno às aulas presenciais acontece timidamente, $\mathrm{e}$ no qual muitos alunos ainda estão acompanhando o ensino remoto em suas residências.

Além da necessária construção de conhecimentos que fazem parte da herança cultural da humanidade, verificamos que a formação de valores socioafetivos que possam ajudar os alunos a ultrapassar este momento crítico passa a ser uma das funções básicas da educação a ser desenvolvida pela escola em todos os níveis, pois, segundo Nascimento e Silva:

Durante a necessidade do distanciamento social e suspensão das atividades presenciais, a crise do novo coronavírus tem sugerido diversos lugares sociais para a escola, e especialmente, o trabalho docente. Para muitos/as, nada parece substituir as relações do cotidiano escolar, para outros/as muitos/as a transmissão do conteúdo e a garantia da realização do ano letivo é o que mais satisfaz. Entre as duas opções está a precariedade das condições de trabalho entre os/as docentes. Precariedades que expõem estruturas da Rede Privada e Pública de Ensino que prescrevem ações pautadas na lógica de mercado em critérios que pouco se aproximam de saúde e bem comum, desvalorizando o papel social da escola e o trabalho docente (2020, p. 80).

À medida que o entrelaçamento da dimensão cognitiva e socioafetiva representa o alvo a ser cultivado doravante pela escola, o trabalho - já precarizado - desenvolvido pelos docentes precisa centralizar-se cada vez mais na formação integral do aluno, capaz de pensar e de avaliar constantemente suas possibilidades, aliadas às várias alternativas e restrições que se impõem neste momento.

Segundo Lahire (2002), o passado se abre aos sujeitos de modos diversos, segundo a natureza de cada um e a configuração que cada sujeito faz da situação presente. Cada um dos alunos terá fatalmente uma representação diferenciada do período em que a pandemia causada pela Covid-19 atingiu todos os povos de maneira indiscriminada, e serão milhares as configurações que este momento ocasionará no desenvolvimento cognitivo e socioafetivo tanto dos professores como dos alunos.

Restam, então, múltiplas perguntas que neste momento são impossíveis de serem respondidas: $O$ que restará deste momento de distanciamento social ocasionado pela pandemia? O que restará desta experiência de ensino remoto para professores e alunos? O que se modificará na identidade do professor no período pós-pandemia? Quais as transformações que acontecerão na profissão docente? Como a escola retomará suas atividades? Como poderá trabalhar a dimensão cognitiva e socioafetiva discente nesse turbilhão de sentimentos e emoções que atingem alunos, professores e famílias dos alunos? Como serão os comportamentos dos alunos em sala de aula? Como se poderá desenvolver (c) (1) 
sentimentos como empatia, autocontrole, autoaceitação, responsabilidade pessoal, assertividade e busca de soluções para conflitos? É possível que o ensino híbrido1 se estabeleça nos processos educacionais das escolas e universidades, mesmo após a pandemia?

Não obstante tantas transformações e incertezas envolvidas, devemos levar em consideração o que é central no processo de ensino-aprendizagem realizado na escola: o ensino calcado na interação entre os sujeitos, o que traz perspectivas do desenvolvimento de ações pedagógicas coletivas. Por isso, por mais que em tempos de pandemia o ensino remoto (ou mesmo o híbrido) tenha ganhado força e relevância na Educação, tais modalidades deixaram ainda mais evidente o quão importante continua sendo o ensino presencial nas escolas de educação básica, o qual esperamos que tão logo retorne, assim que as condições sanitárias do país permitirem. No entanto, o contexto político-social em que nos encontramos é de ambiguidade e insegurança. Para Nascimento e Silva,

O tempo é de incertezas, em que instituições e docentes precisam se reinventar a todo momento, tentando compreender uma nova realidade que a cada dia impõe novos desafios. O vírus não faz escolhas, mas certamente aprofunda a crise social já em curso há anos (2020, p. 91).

Há algumas perguntas que só o tempo poderá responder, já que a incerteza e a perplexidade ainda são enormes por parte de todos, e, justamente por estarmos mergulhados em tantas dúvidas e incoerências, não há, no momento, como ter respostas para tais indagações. Entretanto, as experiências vividas são parte integrante da identidade docente daqui em diante, possibilitando o entendimento das relações do professor com o saber, e com os alunos neste momento marcante (e difícil) da história da educação brasileira.

\section{REFERÊNCIAS}

ARRUDA, Juliana Silva; SIQUEIRA, Liliane Maria Ramalho de Castro.

Metodologias ativas, ensino híbrido e os artefatos digitais: sala de aula em tempos de pandemia. Práticas Educativas, Memórias e Oralidades - Rev. Pemo, v. 3, n. 1, p. e314292, jan. 2021.

ARROYO, Miguel. Ofício de Mestre: imagens e autoimagens. $15^{a}$ edição. Petrópolis: Vozes, 2013.

\footnotetext{
${ }^{1}$ Trata-se de um modelo de ensino em que a aprendizagem é o resultado da mescla de uma proposta escolar mais tradicional (leitura de materiais e aulas expositivas) com formatos mais inovadores (discussões coletivas e atividades de pesquisa). Ao longo do processo há tanto atividades off-line, como propostas digitais. Assim, no ensino híbrido, o aluno aprende uma parte pela modalidade on line, na qual há controle de tempo, lugar, modo e/ou ritmo de estudo, e a outra parte acontece em ambiente físico, fora de sua casa, sob a mediação do professor (ARRUDA; SIQUEIRA, 2021).
} 
DAMASIO, Antonio R. O Erro de Descartes: emoção, razão e o cérebro humano. São Paulo: Companhia das Letras, 1996.

DUBAR, Claude. A socialização: construção das identidades sociais e profissionais. São Paulo: Martins Fontes, 1995.

ESTEVE, José M. Mudanças Sociais e Função Docente. In: NÓVOA, Antonio. (org.). Profissão Professor, 2a ed, Porto, Porto Edt, 1999.

FERREIRA, Fernando Idílio. Identidades dos Professores perspectivas teóricas e metodológicas. In: ESTRELA, Albano; CANÁRIO, Rui; FERREIRA Júlia.

Formação, saberes profissionais e situações de trabalho. Lisboa: VI Colóquio Nacional da AIPELF/AFIRSE, vol. 1, Universidade de Lisboa, 1996, p. 309-328.

GARDNER, Howard. Estrutura da Mente: a teoria das inteligências múltiplas. Porto Alegre: Artes Médicas, 1994.

GOLEMAN, Daniel. Inteligência Emocional. Rio de Janeiro: Objetiva, 1995.

GOLEMAN, Daniel. Inteligência Emocional: a arte de educar nossos filhos. Rio de Janeiro: Objetiva, 1997.

GATTI, Bernardete Angelina. et al. Professores do Brasil: novos cenários de formação. Brasília: UNESCO, 2019.

LAHIRE, Bernard. O homem plural: os determinates da ação. Petrópolis: Vozes, 2002.

MARCHESI, Alvaro. O Bem-estar dos professores: competências, emoções e valores. Porto Alegre: Artmed, 2008.

MARCONDES, Maria Ines; LEITE, Vania Finholdt Angelo. Formação de Professores e Trabalho Docente no Brasil: contexto, questões e desafios na atualidade. In FLORES, Maria Assunção (Org). Formação e desenvolvimento profissional de professores: contributos internacionais. Coimbra: Almedina, 2014, p. 153-169.

MELUCCI, Alberto. $\mathbf{O}$ jogo do Eu: a mudanda de si numa sociedade global. Porto Alegre: Editora Unisinos, 2004.

MORGADO, José Carlos. Identidade e profissionalidade: sentidos e (im)possibilidades. Revista Ensaio: Avaliação e Políticas Públicas

Educacionais. Rio de Janeiro, v. 19,n.73, p 793-812, out/dez/2011.

NASCIMENTO, Erica P.; SILVA, Rita de Cássia de O. Luz, câmera, (desumaniz)ação: entre o pedagógico e a manutenção da vida, o que é ser 
professor/a em tempos de pandemia?. In: Revista Interinstitucional Artes de Educar. Rio de Janeiro, vol. 6 - N. Especial II, jun-out. 2020, p. 75-93.

NÓVOA, António. Os professores e as histórias da sua vida. In NOVOA, A. (ORG). Vida de Professores. Porto: Porto Editora, 1992, p. 11-30.

PIAGET, Jean. O Nascimento da inteligência na criança. Rio de Janeiro: Zahar, 1970.

SASTRE, Genoveva e MORENO, Montserrat. Resolução de conflitos e aprendizagem emocional: gênero e transversalidade. São Paulo, Moderna, 2002.

SAVATER, Fernando. O Valor de Educar. Lisboa: Publicações Don Quixote, 2006.

SILVA, Maria de Lourdes Ramos. Os desafios das contradições socioafetivas na educação escolar e suas influências na formação da cidadania. In: SILVA JR, Jonas; SILVA, Maria de Lourdes Ramos. (ORGS) Formação docente, cidadania e direitos humanos. Curitiba, CRV, 2020.

SILVA, Maria de Lourdes Ramos. Aspectos Sócioafetivos que interferem na construção da identidade do professor. In: SILVA, Elisabeth Ramos; UYENO, Elzira Yoko; ABUD, Maria José. Cognição, afetividade e linguagem. Taubaté, 2007.

TARDIF, Maurice; RAYMOND, Danielle. Saberes, tempo e aprendizagem do trabalho do magistério. Revista Educação e Sociedade, ano XXI, n. 73, Dezembro, 2000, p 209-244.

Recebido em: 03 de março de 2021.

Aceito em: 12 de agosto de 2021. Publicado em: 05 de janeiro de 2022. 